\title{
IMPACTO DA ALTA EVOLUÇÃO DO NÚMERO DE DISCENTES DO CURSO DE GRADUAÇÃO EM ENGENHARIA DE SOFTWARE DA UNIVERSIDADE DE BRASÍLIA
}

\author{
IMPACT OF THE HIGH DEVELOPMENT OF THE NUMBER OF STUDENTS GRADUATION
} COURSE IN SOFTWARE ENGINEERING AT THE UNIVERSITY OF BRASÍLIA André Barros de Sales ${ }^{1}$, Marcelino Monteiro Andrade ${ }^{2}$ DOI: 10.37702/REE2236-0158.v39p441-449.2020

\begin{abstract}
RESUMO
A tecnologia digital conquista mais espaço e está cada vez mais presente no cotidiano das pessoas. Cada vez mais a capacitação e a formação qualificada de profissionais são necessárias na sociedade em que vivemos. Nos últimos anos, o curso de Engenharia de Software da Universidade de Brasília vem apresentando aumento significativo do número de discentes em comparação aos demais cursos da área de Computação e da área de Engenharias. Este artigo objetivou analisar a dispersão de discentes nas disciplinas e em quais períodos do curso de graduação em Engenharia de Software da Faculdade do Gama da Universidade de Brasília estão concentrados os discentes regularmente matriculados. A metodologia neste estudo é de cunho descritivo, com abordagem quantitativa. Os resultados revelaram que o curso de Engenharia de Software registra o maior número de discentes entre os cursos de engenharias da Faculdade do Gama da Universidade de Brasília, cuja maioria está matriculada em disciplinas obrigatórias entre o terceiro e o sexto períodos do curso, predominando as disciplinas do terceiro semestre.
\end{abstract}

Palavras-chave: Engenharia de Software; curso de graduação; número de discentes.

\begin{abstract}
Digital technology gains more space and is increasingly present in people's daily lives. Increasingly, training and qualified training of professionals is necessary in the society in which we live. In recent years, the Software Engineering course at the University of Brasília has significantly increased the number of students compared to other courses in the area of Computing and Engineering. This article aimed to analyze the impact and in which periods of the undergraduate course Software Engineering at the Faculty of Gama of the University of Brasilia are regularly enrolled students. The methodology in this study is descriptive, with a quantitative approach. The results revealed that the Software Engineering course registers the largest number of students among the engineering courses at the Faculty of Gama of the University of Brasilia, most of which are enrolled in mandatory subjects between the third and sixth period of the course, with a predominance of subjects the third semester.
\end{abstract}

Keywords: Software Engineering; undergraduate course; number of undergraduate students.

\footnotetext{
${ }^{1}$ Professor Associado. Faculdade do Gama, Universidade de Brasília (UnB); andrebdes@unb.br

${ }^{2}$ Professor Associado. Faculdade do Gama, Universidade de Brasília (UnB); andrade@unb.br
} 


\section{INTRODUÇÃO}

Com os avanços tecnológicos e científicos nas últimas décadas, cresce cada vez mais a necessidade de profissionais qualificados para o mercado de trabalho. Entre os cursos de graduação na área da Computação está o curso de Engenharia de Software.

A Universidade de Brasília (UnB) oferece cinco cursos na área de Computação (Bacharelado em Ciência da Computação, Engenharia de Computação, Licenciatura da Computação, Engenharia Mecatrônica e Engenharia de Software).

A evolução do número de discentes regularmente registrados nos cursos de graduação de 2014 para 2018 foi: Bacharelado em Ciência da Computação - de 381 para 408; Engenharia de Computação - de 329 para 420; Licenciatura da Computação - de 300 para 346; Engenharia Mecatrônica - de 391 para 418; e Engenharia de Software - de 297 para 575 (Anuário Estatístico, 2019). Importante enfatizar que no que diz respeito ao curso de Engenharia de Software o aumento de discentes matriculados foi superior a $95 \%$ no período 2014/2018.

Em relação ao número de formados, o Anuário Estatístico da UnB de 2019 mostra que, de 2014 a 2018, a evolução foi a seguinte: Bacharelado em Ciência da Computação - de 26 para 36; Engenharia da Computação - de 9 para 36; Licenciatura da Computação - de 19 para 19; Engenharia Mecatrônica - de 26 para 30; e Engenharia de Software - de 34 para 55. Observa-se ainda um necessário crescimento do número de formados em relação ao número de matriculados no curso de Engenharia de Software.

$\mathrm{O}$ curso de Bacharelado em Engenharia de Software da Universidade de Brasília - UnB foi o primeiro do Brasil e começou no segundo semestre de 2008, seguido pelo curso da Universidade Federal de Goiás (UFG), em 2009, e os da Universidade Federal do Ceará (UFC), da Universidade Federal do Pampa (UNIPAMPA) e da Universidade Federal do Rio Grande do Norte (UFRN), todos em 2010.

O curso de Engenharia de Software da UnB é localizado no campus da Faculdade do Gama
(FGA), criado no contexto do Programa de Apoio a Planos de Reestruturação e Expansão das Universidades Federais (REUNI, 2007), instituído pelo Decreto $n^{\circ}$ 6.096/2007.

A Faculdade de Gama oferece 280 vagas semestrais (entrada única) para os cinco cursos de graduação em Engenharia Aeroespacial, Engenharia Automotiva, Engenharia de Energia, Engenharia Eletrônica e Engenharia de Software, com esperadas 56 vagas para cada curso.

Todos os cursos de engenharias da Faculdade do Gama possuem a duração de 10 períodos, ou seja, de cinco anos. O discente do curso de Engenharia de Software pode concluir o curso no período máximo em 16 semestres, ou seja, 8 anos.

No projeto de Darcy Ribeiro para criação da UnB, o discente tem a oportunidade de optar por uma orientação profissional quando mais amadurecido e mais bem informado sobre os diferentes campos aos quais poderia devotar-se (RIBEIRO, 2011). Ao ingressar na Faculdade do Gama, o discente entra, então, para o "Ciclo Básico" das Engenharias, podendo, após o primeiro semestre, optar por uma das cinco engenharias. Até o momento, não há nenhuma restrição de quando e quantos discentes devem optar para o curso almejado.

O Projeto Pedagógico do Curso - PPC da Engenharia de Software da FGA, em sua primeira versão (PPC v.1), fundamentou-se principalmente nas diretrizes do Software Engineering $2004 \quad$ (IEEE-CS/ACM) (LEBLANC et al., 2006), Conselho Nacional de Educação - CNE/CES n. 11, de 11/03/2002, Currículo de Referência da Sociedade Brasileira de Computação (SBC, 2005) e Modelos de Processos de Software (CMMI e MPS.BR) (FIGUEIREDO et al., 2010).

Convém salientar que a segunda versão do Projeto Pedagógico do Curso - PPC da Engenharia de Software da FGA (PPC v.2), em outubro de 2016, seguiu a Resolução n. 5/2016 (Resolução CNE/CES, 2016) na orientação da formação profissional por habilidades e competências (WANDER et al., 2012).

Diversos questionamentos surgem na busca por uma resposta ou respostas sobre o aumento de discentes matriculados no curso de 
Engenharia de Software. Alguns desses questionamentos estão relacionados a fatores internos e externos à Universidade. Entre fatores externos está a grande oferta de estágio renumerado de 20 horas. Esses fatores externos não fazem parte deste estudo.

Entre os fatores internos estão as seguintes questões/hipóteses: quantidade de discentes por ano no curso, existem disciplinas retendo os discentes em um determinado período, um grande crescimento discente em um determinado ano específico. Este estudo é a primeira etapa para se iniciar a responder algumas dessas perguntas.

Em consonância com os Projetos Pedagógico dos Cursos da Faculdade do Gama, de entrada única com as demais engenharias acima citadas, surge a seguinte pergunta de pesquisa: onde se encontram os discentes matriculados no fluxo semestral do curso Engenharia de Software? Diante do exposto e para responder tal pergunta, o objetivo deste estudo é analisar em quais períodos estão concentrados os discentes regularmente registrados que optaram pelo curso de graduação Engenharia de Software da Faculdade do Gama da Universidade de Brasília.

Este artigo está assim organizado: a seguir apresenta-se a metodologia; depois os resultados; e, posteriormente, são tecidas as considerações finais.

\section{METODOLOGIA}

Em termos de objetivos, o estudo é de cunho descritivo (GERHARDT; SILVEIRA, 2009). Foi utilizado o tratamento de dados quantitativo e apresentados os resultados de forma descritiva, envolvendo um estudo de caso realizado no curso de graduação em Engenharia de Software da Faculdade do Gama da UnB.

A criação do curso de Engenharia de Software da UnB aconteceu no $2^{\circ}$ semestre de 2008. Foram analisados os dados de todas as disciplinas do ciclo básico, obrigatórias nos cinco cursos da Faculdade do Gama, e de todas as disciplinas obrigatórias do curso de Engenharia de Software ofertadas na Faculdade do Gama no $1^{\circ}$ semestre de 2020 (turmas e matrículas), totalizando os 10 semestres. No seu início, o curso apresenta até sete disciplinas obrigatórias, enquanto nos últimos períodos pode-se chegar em apenas duas ou mesmo uma disciplina obrigatória no período.

Os dados foram solicitados aos responsáveis pelo Sistema de Graduação (SIGRA). Para preservação de suas identidades, os discentes não foram identificados pelo nome; para fins de análise, utilizou-se a matrícula dos discentes.

Para a compreensão dos dados, foi feito um brainstorming entre os pesquisadores com observação sistemática. Primeiramente, foram analisados o fluxo de disciplinas por período do curso de Engenharia de Software ${ }^{3}$, as disciplinas obrigatórias e as optativas. No presente estudo, apenas as disciplinas obrigatórias.

Foram desenvolvidas rotinas para computar o número de matrículas dos discentes do curso de Engenharia de Software em cada turma do fluxo do curso do $1^{\circ}$ semestre de 2020. A análise foi dividida em dois grupos: no primeiro grupo os discentes pertencentes ao fluxo de disciplinas do PPC v. 1; no segundo os discentes pertencentes ao PPC v. 2. No intuito de facilitar a apresentação, esses dados foram plotados em gráficos. Por último, uma breve redação com a análise dos dados.

\section{DISCUSSÃO DOS RESULTADOS}

Foram identificadas matrículas de 650 discentes do curso de Engenharia de Software, estando pendente a finalização da matrícula em algumas disciplinas dos últimos períodos do curso até a data da obtenção dos dados, como Estágio Curricular, Trabalho de Conclusão de Curso 1 (TCC 1) e Trabalho de Conclusão de Curso 2 (TCC 2).

O Gráfico 1 mostra o número total de discentes matriculados em algumas disciplinas

\footnotetext{
${ }^{3}$ Ver mais em:

https://matriculaweb.unb.br/graduacao/fluxo.aspx?cod=6360
} 
do ciclo básico de obrigatórias, por curso da Faculdade do Gama.

Conforme esperado, o curso com maior número de discentes é o Ciclo Básico, com 669 discentes. $\mathrm{O}$ segundo com mais discentes matriculados é o curso de Engenharia de Software, com 650 discentes, seguido pelo Engenharia Eletrônica com 330 discentes.
Os cursos com menor número de discentes matriculados são Engenharia Automotiva e Engenharia de Energia, com 156 e 204 respectivamente. É notória a opção dominante dos discentes da Faculdade do Gama pelo curso de Engenharia de Software, hoje em número proporcional aos estudantes do ciclo básico.

Gráfico 1 - Número de discentes matriculados nas disciplinas obrigatórias da FGA

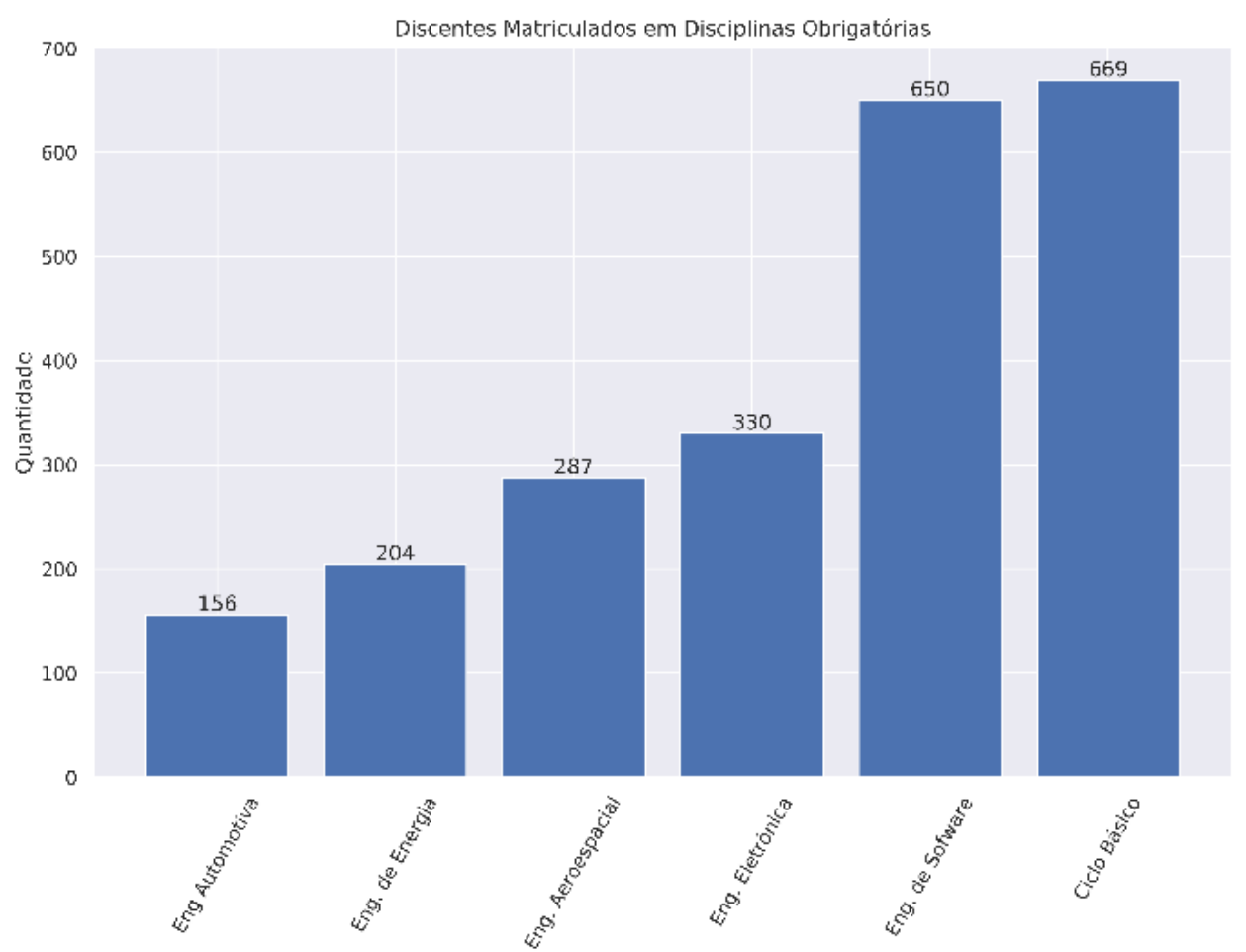

Fonte: elaborado pelos autores.

Essa maior procura por parte dos discentes pelo curso de Engenharia de Software, em relação aos demais cursos, pode estar relacionada a diversos fatores internos do curso, dentre eles à capacidade de manutenção dos estudantes (estágios renumerados e a possibilidade de permanecer no curso até 8 anos), como também à evasão nos demais cursos de engenharias do Campus UnB-Gama.

$\mathrm{O}$ número de matrícula dos discentes da UnB é um número de 9 dígitos, sendo que os dois primeiros representam o ano de entrada do discente na UnB. O Gráfico 2 mostra a quantidade de discentes do curso de Engenharia de Software separados pelo ano de entrada na UnB (primeiro e segundo semestre) que estão matriculados em alguma disciplina obrigatórias do curso na Faculdade do Gama.

O curso de Engenharia de Software é projetado para ser concluído em cinco anos, ou seja, em 10 períodos. Os discentes do curso que ingressaram na UnB antes 2016 são discentes que podem não ter cursado as disciplinas recomendadas em cada semestre, ou que podem ter usufruído de algum trancamento de disciplina ou de curso, ou ter reprovado em alguma disciplina, atrasando a conclusão do curso. 


\section{Gráfico 2 - Número de discentes de Engenharia de Software separados pelo ano de ingresso matriculados nas disciplinas obrigatórias da FGA}

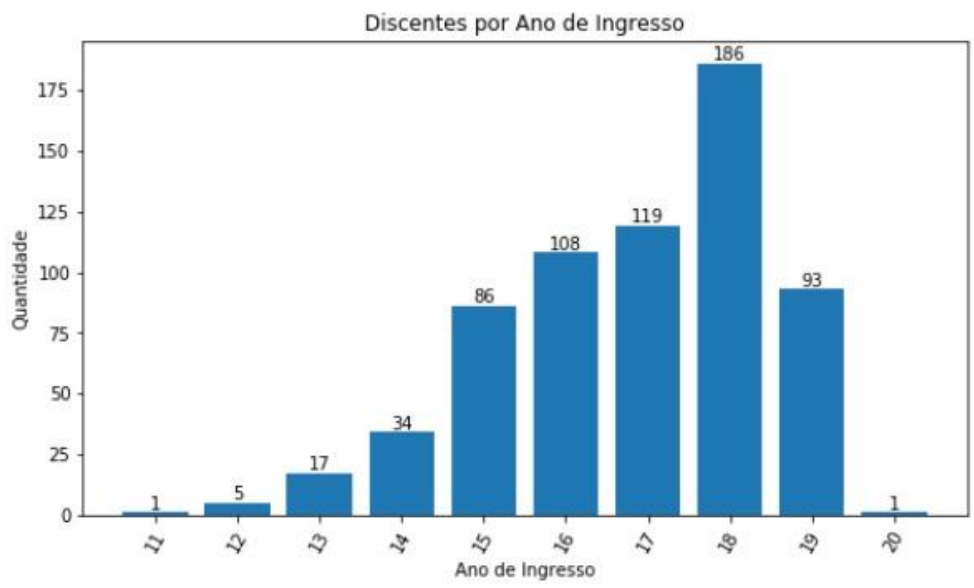

Fonte: elaborado pelos autores.

O curso de Engenharia de Software foi projetado para uma entrada semestral de 56 discentes, ou seja, com uma entrada anual de 112 discentes.

Para os discentes que entraram na UnB nos anos de 2016 e 2017, o curso de Engenharia de Software está com a quantidade de discentes para a qual ele foi projetado. Contudo, a quantidade de discentes ingressantes no curso de Engenharia de Software em 2018 ultrapassou a quantidade projetada em 74 discentes.

Em 2019, 93 discentes optaram pelo curso de Engenharia de Software, o que representa uma quantidade com 19 discentes abaixo do esperado. Contudo, cabe ressaltar que nem todos os discentes fizeram a opção de curso. Os discentes que entraram no segundo semestre de 2019 podem optar pelo curso a partir do início do primeiro semestre de 2020.

Os discentes podem optar por uma das engenharias após cursar um semestre na UnB. Observa-se, ainda no Gráfico 2, que um discente que ingressou em 2020 já pertence ao curso de Engenharia de Software. Esse discente ingressante em 2020 é um ex-aluno da UnB que voltou a cursar o curso de Engenharia de Software. Este já possuí 30 créditos de tal curso.

O Gráfico 3 mostra o número de matrículas nas disciplinas obrigatórias do curso de
Engenharia de Software por período. Para melhor visualização, foi omitido os nomes das disciplinas ${ }^{4}$.

Gráfico 3 - Número de matrículas de discentes em disciplinas, com repetição de matrícula, por período do curso de Engenharia de Software

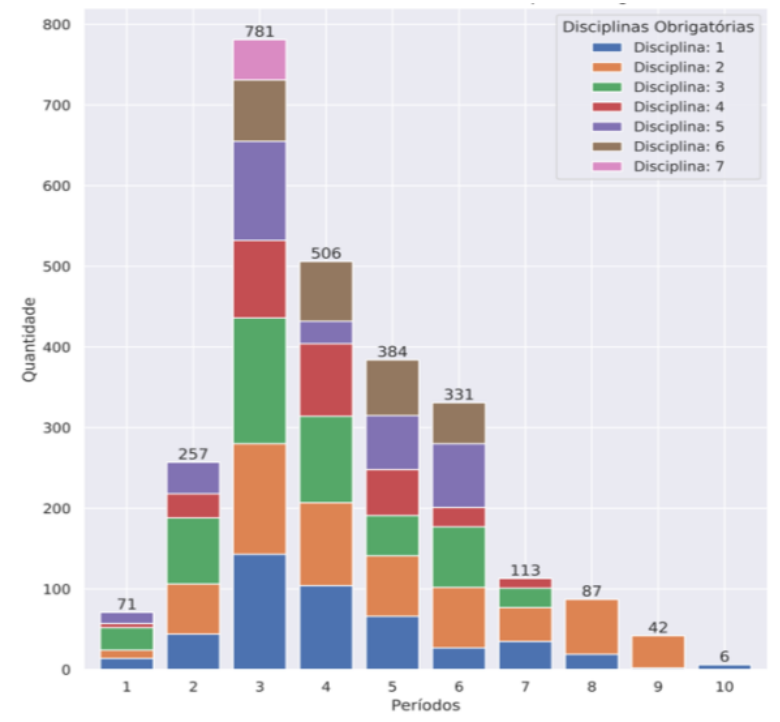

Fonte: elaborado pelos autores.

As disciplinas que têm o maior número de discentes matriculados estão concentradas no terceiro período do curso, com 781 matrículas nas sete disciplinas desse período, cabendo ressaltar que um mesmo discente pode estar

${ }^{4} \mathrm{O}$ fluxo do curso de Engenharia de Software pode ser visto em: https://matriculaweb.unb.br/graduacao/fluxo.aspx? cod=6360. 
matriculado até nas sete disciplinas desse período. Caso o discente esteja matriculado em apenas uma disciplina, a matrícula dele será contada apenas uma vez. Caso ele esteja matriculado nas sete disciplinas, a matrícula dele será contada sete vezes. Essa contagem é necessária para que seja possível analisar se alguma disciplina possui uma quantidade maior em número de discentes matriculados que outra.

O quarto período, com 506 matrículas, é o segundo com maior número de discentes matriculados. Os Gráficos 4 e 5 apresentam o número de matrículas por período do curso de Engenharia de Software: no Gráfico 4, com o número de matrículas dos discentes pertencentes ao PPC v. 1; no Gráfico 5, com os discentes do PPC v. 2.

Cabe salientar que discentes regularmente registrados no curso de Engenharia de Software no PPC v. 1 são 205 e do PPC v. 2 são 445. Estudantes matriculados no terceiro período do curso de Engenharia de Software no PPC v. 2 somam 258.

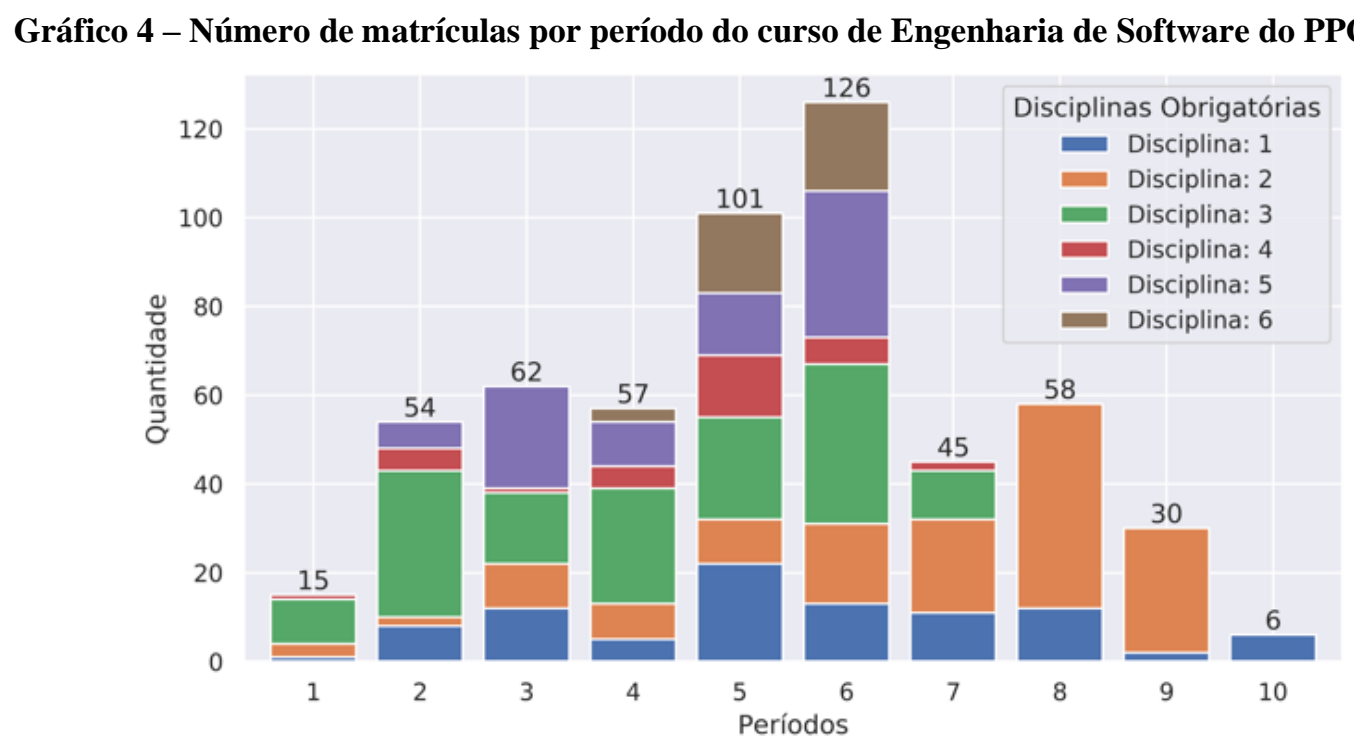

Fonte: elaborado pelos autores.

Gráfico 5 - Número de matrículas por período do curso de Engenharia de Software do PPC v. 2

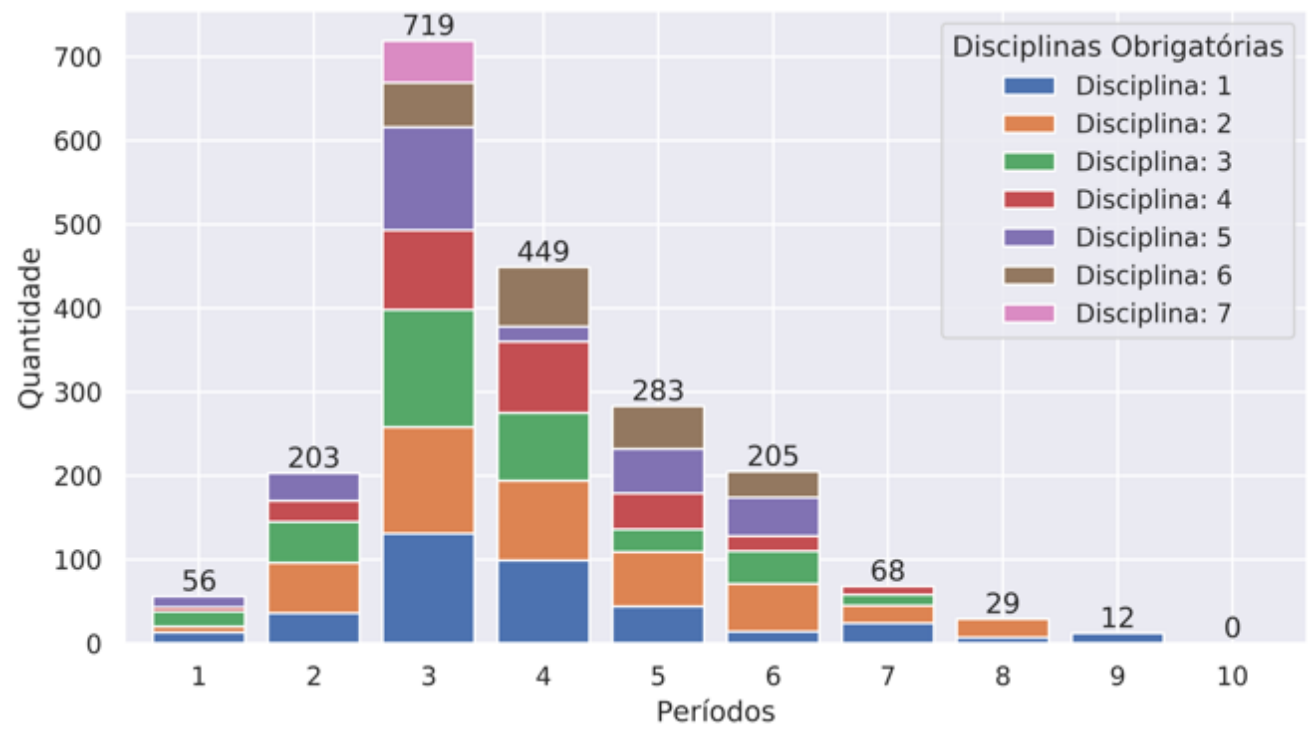

Fonte: elaborado pelos autores. 
Gráfico 6 - Percentual de matrículas por período do curso de Engenharia de Software dos discentes do PPC v. 2

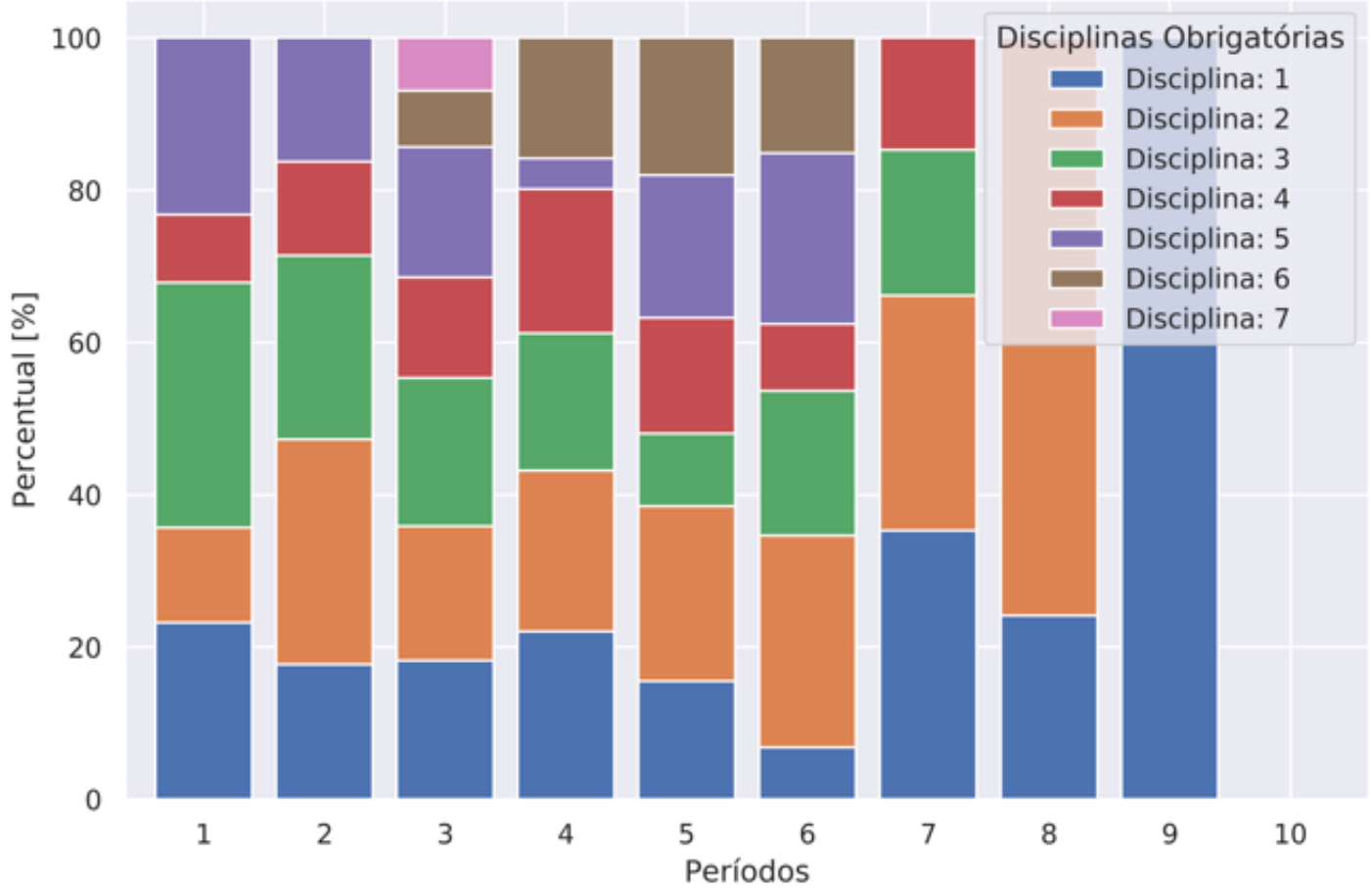

Fonte: elaborado pelos autores.

Gráfico 7 - Distribuição do ano de entrada das matrículas por período do curso de Engenharia de Software do PPC v. 2

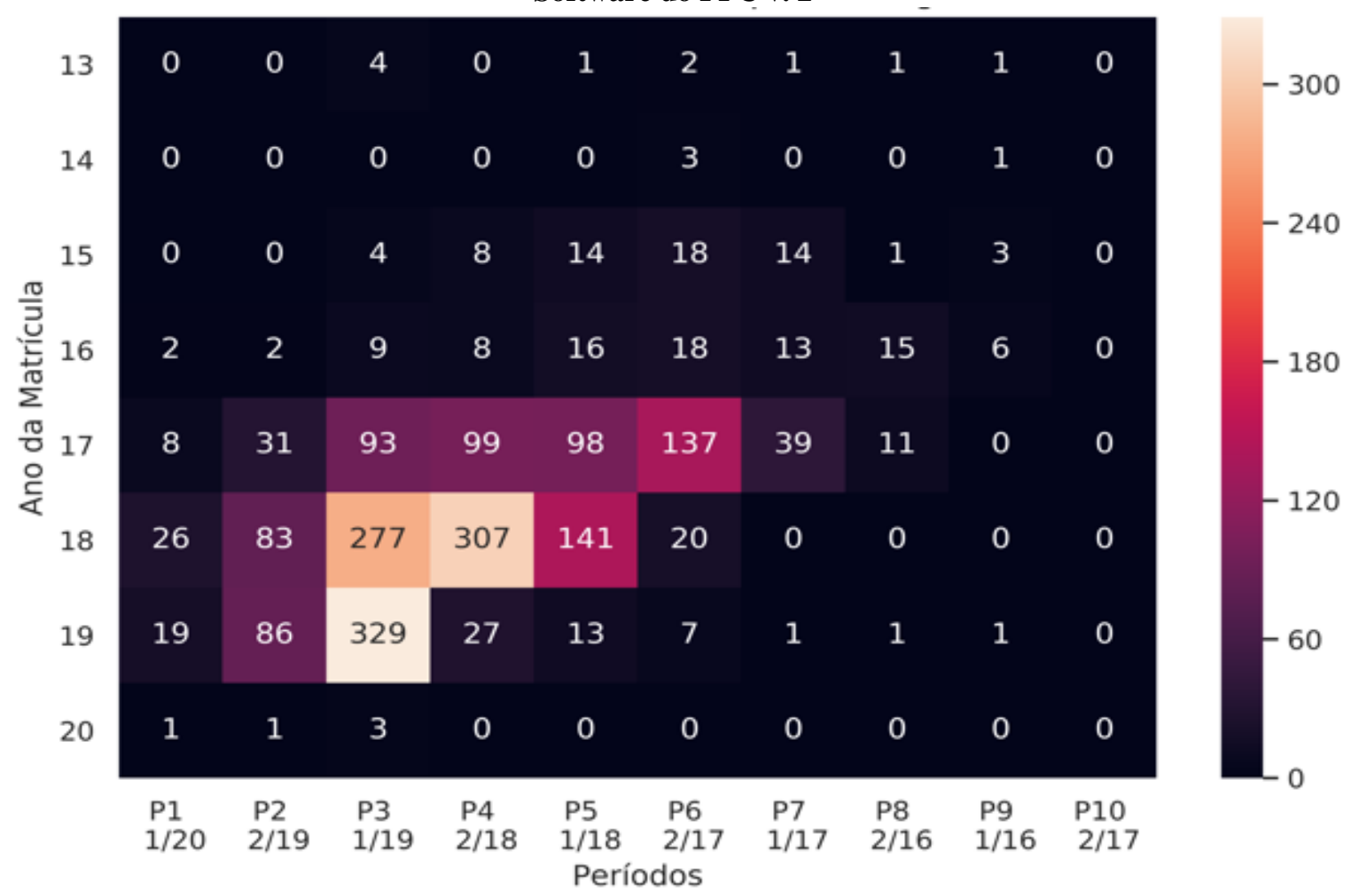

Fonte: elaborado pelos autores. 
É observável no Gráfico 6 uma boa variabilidade de disciplinas e tamanhos de turmas durante os seis primeiros períodos do curso de Engenharia de Software, estando todas ocupadas no limiar das vagas oferecidas. As matrículas dos últimos períodos do curso de Engenharia de Software, a partir do oitavo período, não haviam sido finalizadas até a data da obtenção dos dados, como exemplo as disciplinas Estágio Curricular, TCC 1 e TCC 2.

O Gráfico 7 mostra a distribuição das matrículas dos discentes por ano de entrada ao longo dos períodos do curso de Engenharia de Software. A maior concentração de matrículas, acima de 200, nas disciplinas obrigatórias, encontra-se entre o terceiro e o sexto período. No primeiro e segundo semestre há baixa quantidade de discentes do curso de Engenharia de Software, pois ainda não optaram pelo curso.

A evolução do número de discentes matriculados no curso de graduação de Engenharia de Software nos últimos dois anos deverá impactar todas as disciplinas do fluxo subsequente nos próximos anos. O presente estudo mostra o contexto atual do curso de Engenharia de Software que servirá para o planejamento e a gestão do curso nos próximos semestres.

\section{CONSIDERAÇÕES FINAIS}

Este artigo apresentou a evolução do número de discentes regularmente registrados nos cursos da área de Computação, principalmente no curso de Engenharia de Software. Os resultados revelaram que o curso de Engenharia de Software é dominante em número de discentes entre os cursos de engenharias da Faculdade do Gama da Universidade de Brasília; os discentes estão majoritariamente matriculados em disciplinas obrigatórias entre o terceiro e o sexto período do curso, sendo o terceiro semestre o que detém o maior número de matrículas.

Com base nos resultados do estudo nas disciplinas obrigatórias, evidencia-se a evolução do número de discentes regularmente registrados no curso de graduação de Engenharia de Software nos últimos dois anos, fato que deverá impactar em todas as disciplinas subsequentes nos próximos anos. Este estudo contribui para apresentar o contexto atual do curso de Engenharia de Software e servirá para o planejamento e a gestão do curso nos próximos semestres.

Os atrativos para os discentes optarem pelo curso de Engenharia de Software se prendem a diversas razões. Assim, para trabalhos futuros (já em andamento), pretende-se a realização de um levantamento dos motivadores da escolha do curso de Engenharia de Software na Faculdade do Gama pelos discentes. Também em andamento se encontram: análise dos motivos de retenção dos discentes no curso de graduação, investigação dos dados do perfil dos discentes e dos egressos. Além disso, fica ainda para um próximo trabalho a análise estatística dos resultados desta pesquisa.

\section{REFERÊNCIAS}

\author{
ANUÁRIO ESTATÍSTICO UNB. Anuário \\ Estatístico da UnB 2019. Período: 2014 a 2018. \\ Universidade de Brasília, 2019. Disponível em \\ http://dpo.unb.br/index.php?option=com_content\& \\ view $=$ article $\&$ id $=60$ :apresentacao-anuario- \\ estatistico\&catid=198: anuario-estatistico- \\ 2019\&Itemid=896. Acesso em: 18 fev. 2020.
}

BRASIL. Ministério da Educação. Resolução CNE/CES 5/2016. Diretrizes Curriculares dos Cursos de Bacharelado em Ciência da Computação, Engenharia de Computação, Engenharia de Software e Sistemas de Informação e dos Cursos de Licenciatura em Computação. Diário Oficial da União, Brasília, Seção 1, págs. 22-24, 2016.

FIGUEIREDO R. M. et al. Teaching Software Quality in an Interdisciplinary Course of Engineering. Anais... 7th International Confer. on the Quality of Information and Communications Technology (QUATIC), p. 144-149, 2010.

GERHARDT, T. E.; SILVEIRA, D. T. (Orgs.). Métodos de pesquisa. Série Educação a Distância. Porto Alegre: Editora da UFRGS, 2009.

LEBLANC, R. et al. Software Engineering 2004: Curriculum Guidelines for Undergraduate Degree Programs in Software Engineering. IEEE, Los Alamitos, CA, 2006. 
REUNI. REUNI - Diretrizes Gerais. Plano de Desenvolvimento da Educação, 2007. Disponível em:

http://portal.mec.gov.br/sesu/arquivos/pdf/diretrize sreuni.pdf. Acesso em: 18 fev. 2020.

RIBEIRO, D. Universidade de Brasília: Projeto de Organização, Pronunciamento de Educadores e Cientistas. Editora: Edu - UnB, 2011.

SBC. Currículo de Referência da SBC para Cursos de Graduação em Bacharelado em Ciência da Computação e Engenharia de Computação. Proposta versão 2005. Diretoria de Educação, Sociedade Brasileira de Computação.
2005.

Disponível

em: http://www.sbc.org.br/documentos-dasbc/summary/131-curriculos-dereferencia/760curriculo-de-referencia-cc-ec-versao2005. Acesso em: 18 fev. 2020.

WANDER, C. M. P. da S. et al. A elaboração da nova Matriz Curricular do Curso de Engenharia de Software da UnB: uma proposta de método baseado na Educação por Competências. Anais... V Fórum de Educação em Engenharia de Software (FEES/SBES), Natal, 2012.

\section{DADOS BIOGRÁFICOS DOS AUTORES}

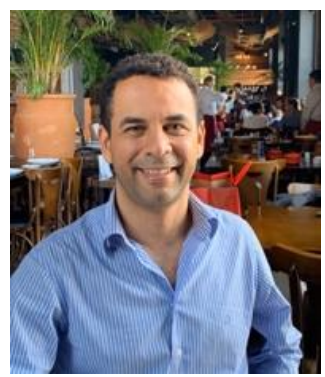

André Barros de Sales - Graduado em Tecnologia em Processamento de Dados pelo Instituto Unificado de Ensino Superior Objetivo em 1993, mestre em Ciência da Computação pela Universidade Federal de Santa Catarina (2000) e doutor em Ciência da Computação pela Université Paul Sabatier, em Toulouse, França, em 2004. Atua como professor Associado na Faculdade de Gama da Universidade de Brasília (UnB) desde 2008. ORCID: https://orcid.org/0000-0002-1728-6063.

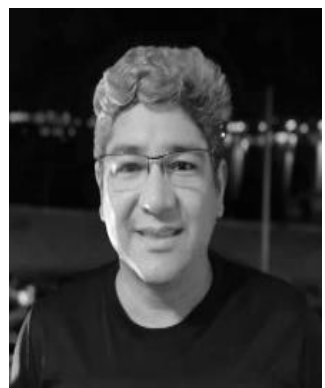

Marcelino Monteiro Andrade - Graduado em 1997, mestre em 2000 e doutor em 2006, todas as titulações em Engenharia Elétrica pela Universidade de Brasília. Atua como professor Associado na Faculdade de Gama da Universidade de Brasília (UnB) desde 2008. 